\title{
HERMITE-HADAMARD-TYPE INEQUALITIES FOR RADAU-TYPE QUADRATURE RULES
}

\section{IVA FRANJIĆ}

Abstract. Hermite-Hadamard-type inequalities are given for Radau-type quadrature rules and $k$-convex functions (where $k=2,3,5$ ). Furthermore, the best possible error estimates for the Radau-type quadrature rules and functions with low degree of smoothness are obtained.

Mathematics subject classification (2000): 26D15, 65D30, 65D32.

Keywords and phrases: Hermite-Hadamard-type inequalities, $k$-convex functions, Radau-type quadrature rules, extended Euler formulae, Bernoulli polynomials.

\section{REFERENCES}

[1] M. Abramowitz And I. A. Stegun (EDS), Handbook of mathematical functions with formulae, graphs and mathematical tables, National Bureau of Standards, Applied Math.Series 55, 4th printing, Washington, 1965.

[2] M. BessenyeI, Hermite-Hadamard-type inequalities for generalized convex functions, Ph.D. dissertation (2005), Journal of Inequal. in Pure and Appl. Math., 9, 3 (2008), art.63, 51pp.

[3] M. Bessenyei, Z. PÁles, Higher-order generalizations of Hadamard's inequality, Publ. Math. Debrecen, 61, 3-4 (2002), 623-643.

[4] P. J. Davis, P. RabinowitZ, Methods of Numerical Integration, New York, 1975.

[5] LJ. Dedić, M. MATIĆ, J. PEČARIĆ, On generalizations of Ostrowski inequality via some Euler-type identities, Math. Inequal. Appl., 3, 3 (2000), 337-353.

[6] V. I. KRYLOV, Approximate calculation of integrals, Macmillan, New York-London, 1962. 